\title{
Seasonal variation in agronomic characteristics and sugar content of cabbage genotypes
}

\author{
Shiva Ram Bhandari ${ }^{1}$, Chang Sun Choi ${ }^{2}$, Juhee Rhee ${ }^{3}$, Jung Su Jo ${ }^{1}$, Yu Kyeong Shin ${ }^{1}$, \\ Jae Woo Song ${ }^{1}$, and Jun Gu Lee ${ }^{1,4^{*}}$

\begin{abstract}
${ }^{1}$ Jeonbuk National University, College of Agriculture \& Life Sciences, Department of Horticulture, Jeonju 54896, Korea. ${ }^{2}$ Breeding Research Institute, Koregon Co., Ltd., Gimje 54324, Korea.

"Corresponding author (jungu@jbnu.ac.kr).
\end{abstract} \\ ${ }^{3}$ National Agrobiodiversity Center, National Institute of Agricultural Sciences, Rural Development Administration, Jeonju 54874, Korea. \\ ${ }^{4}$ Jeonbuk National University, Institute of Agricultural Science \& Technology, Jeonju 54896, Korea.
}

Received: 17 June 2020; Accepted: 20 September 2020; doi:10.4067/S0718-58392021000100080

\begin{abstract}
Cabbage is one of the most popular vegetables that is rich in sugars contributing to flavor and consumer acceptance; however, little information is available on the effect of genotypes and growing conditions on sugar accumulation. We assessed the seasonal variation in agronomic characteristics and free sugar content in cabbage (Brassica oleracea L. var. capitata L.) grown under open field conditions. Seventy-five cabbage genotypes were grown in the spring and autumn 2019, and their morphological characteristics and sugar concentrations were evaluated. Six cabbage types produced predominantly round-shaped heads (64 genotypes). Bright green and green were the dominant colors depending on the outer and inner leaves of the cabbage head. The most variable quantitative trait was head weight in both spring (36.9\%) and autumn (49.2\%). Glucose was the predominant sugar in most genotypes in both seasons. Mean glucose content in spring and autumn was 209.3 and $214.9 \mathrm{mg} \mathrm{g}^{-1}$ with $14.8 \%$ and $14.6 \%$ variation, respectively. Most genotypes produced higher fructose concentrations in fall than in spring. Sucrose levels showed the highest variation in both spring (36.0\%) and autumn (60.5\%), followed by fructose and glucose levels. Most agronomic parameters exhibited nonsignificant or negative correlations with sugar content, except the correlation of head height and width with glucose content. Fructose and glucose were positively correlated with total sugar content, while there was nonsignificant correlation with sucrose. Genotypes 160330 and 183701 produced comparably high and stable total sugar content in both seasons and can therefore be used as commercial breeding materials. We revealed a significant effect of genotype and season on cabbage agronomic characteristics and sugar content.
\end{abstract}

Key words: Agronomic characteristics, Brassica oleracea var. capitata, fructose, genetic variation, glucose, growing season.

\section{INTRODUCTION}

Cabbage (Brassica oleracea L. var. capitata L.) is one of the most important brassicaceous crops and it is grown worldwide. The cultivated area and annual production of cabbage in South Korea is 7906 ha and 371651 t, respectively (Korean Statistical Information Service, 2018). Cabbage is commonly consumed as salad, boiled leaves, juice, fermented products, and stir-fry. This plant shows substantial variability in its genetics and morphological characteristics (Balkaya et al., 2005; Kibar et al., 2016), which is important to genetically improve any particular characteristic. Many epidemiological studies have reported that the consumption of Brassica crops, including cabbage, is associated with reducing the risk of chronic diseases and cancer incidence (Terry et al., 2001; Wu et al., 2013). Cabbage exhibits antioxidant, chemo-preventive, and anti-obesity properties (Williams et al., 2013; Samec et al., 2017; Koss-Mikolajczyk et al., 2019), and it is also used 
in traditional medicine (Samec et al., 2017). Cabbage is also a good source of dietary fiber. Such beneficial effects of cabbage have been mainly attributed to its glucosinolates, phenols, flavonoids, anthocyanins, carotenoids, vitamins, and carbohydrates (Park et al., 2014; Koss-Mikolajczyk et al., 2019; Bhandari et al., 2020; Zhao et al., 2020).

Carbohydrates are primary compounds of the metabolism of plants that can be used as energy sources for vegetative growth and development. These compounds can be immediately transported or temporarily stored and are precursors in the biosynthesis of different compounds, including proteins, lipids, and polysaccharides (Rosa et al., 2001; Eveland and Jackson, 2012; Ciereszko, 2018). Carbohydrates serve as signaling molecules that affect enzyme activity and gene expression and help to regulate plant growth and development (Eveland and Jackson, 2012). Free sugars, specifically sucrose, serve as anti-oxidative agents under abiotic stress conditions (Keunen et al., 2013). Sweetness is determined by differential concentrations of fructose, glucose, and sucrose in which fructose contributes the most to sweetness, followed by sucrose and glucose (Joesten et al., 2007). They also may alter flavor and palatability of vegetables in various ways (VandenLangenberg et al., 2012) and help to perceive flavors associated with other organic compounds (Auerswald et al., 1999). Furthermore, higher sugar concentrations can mask the bitter taste of $S$ compounds such as glucosinolates, which increase palatability (Schonhof et al., 2004). The accumulation and relative concentration of sugars depends on several factors such as genotype, tissue type, plant developmental stages, and growing season (Rosa et al., 2001; Aires et al., 2011; VandenLangenberg et al., 2012; Bhandari and Kwak, 2015a; Zhao et al., 2020).

Several studies have been conducted to assess the effects of genotype, growing season, postharvest conditions, and plant parts on a range of bioactive compounds in cabbage, including glucosinolates, vitamins, phenols, and flavonoids (Banerjee et al., 2014; Choi et al., 2014; Ciska et al., 2016; Pessoa et al., 2016; Bhandari et al., 2020; Zhao et al., 2020). However, information regarding sugar composition is limited to a few genotypes (Rosa et al., 2001). The effect of the growing season on sugar content in cabbage heads has not been examined in detail. Genotype and growing conditions are important parameters for phytochemical accumulation, so that genotypes producing high and stable free sugar concentrations under various environmental conditions should be identified. Variability in agronomic characteristics between several cabbage genotypes was previously studied (Singh et al., 2010; Kibar et al., 2016), but the effects of origin and season on changes in such agronomic parameters are yet unclear.

We examined genotypic and seasonal variation in agronomic characteristics and free sugar content of 75 cabbage genotypes grown under open field conditions in spring and autumn to identify genotypes with high sugar content and favorable agronomic parameters, which can be used for commercial breeding.

\section{MATERIALS AND METHODS}

\section{Plant material and cultivation}

Seeds of 75 cabbage (Brassica oleracea L. var. capitata L.) genotypes were obtained from the National Agrobiodiversity Center, Jeonju, South Korea. Common names, accession numbers, and source details are shown in Table 1. Plants were grown at the Breeding Research Institute of the Koregon Co. (Gimje, South Korea) in two seasons. Seeds were sown in 72-cell trays on 10 March and 31 July 2019 for the spring and autumn growing periods, respectively. Approximately 30 $\mathrm{d}$ after sowing, seedlings were transplanted to an experimental field (Breeding Research Institute of the Koregon Co.) where they were planted in rows with $30 \mathrm{~cm}$ spacing between plants and $100 \mathrm{~cm}$ spacing between rows. Base fertilizer had been applied to the experimental field according to the study by Bhandari et al. (2020). Compost fertilizer ( $\left.3700 \mathrm{~kg} \mathrm{ha}^{-1}\right)$ was applied during the experiment. Plants were irrigated with sprinklers every day in the morning. Cabbage heads were first harvested $40 \mathrm{~d}$ after transplanting, depending on the genotype. Meteorological data were collected from a weather station close to the experimental field from the date of transplanting to harvesting in both seasons (Figure 1). Leaf length was measured during harvest. Three cabbage heads of each genotype were used for sampling. Once harvested, cabbage heads were immediately taken to the laboratory and two to three outer leaves were removed to account for contamination with dust particles. The shape and color of the outer and inner leaves were evaluated. Head weight, height, width, and core length were measured. Each cabbage head was vertically cut into four parts with a knife and one part of each head was then cut into small pieces that were freeze-dried at $-54{ }^{\circ} \mathrm{C}$, ground into a fine powder, and stored at $-20{ }^{\circ} \mathrm{C}$ until sugar analysis. Cabbage head shape and outer and inner leaf color were only evaluated in spring and all other measurements were recorded in both seasons. The leaf color was visually determined at harvest. 
Table 1. Seasonal variation in agronomic characteristics of cabbage genotypes.

\begin{tabular}{|c|c|c|c|c|c|c|c|c|c|c|c|c|c|c|c|c|}
\hline \multirow[b]{2}{*}{$\mathrm{SN}$} & \multirow[b]{2}{*}{ Number } & \multirow[b]{2}{*}{ Resource name } & \multirow[b]{2}{*}{ Origin $^{1}$} & \multirow{2}{*}{$\begin{array}{l}\text { Head } \\
\text { shape }\end{array}$} & \multirow{2}{*}{$\begin{array}{l}\text { Outer } \\
\text { leaf } \\
\text { color }\end{array}$} & \multirow{2}{*}{$\begin{array}{c}\text { Inner } \\
\text { leaf } \\
\text { color }\end{array}$} & \multicolumn{2}{|c|}{ Leaf length } & \multicolumn{2}{|c|}{ Head weight } & \multicolumn{2}{|c|}{ Head height } & \multicolumn{2}{|c|}{ Head width } & Cor & ength \\
\hline & & & & & & & Spring & . & Sprii & Autumn & Spring & tur & spring & tum & pring & Autumn \\
\hline & & & & & & & & $\mathrm{m}$ & 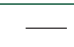 & $\mathrm{g}-$ & - & $\mathrm{m}-$ & - & $\mathrm{m}-$ & - & $\mathrm{m}$ \\
\hline 1 & 160330 & Jing Li 1 & $\mathrm{CHN}$ & Flat & BRG & BRG & 34.0 & 32.8 & 1070 & 2124 & 12.0 & 13.5 & 20.0 & 27.0 & 5.5 & 6.3 \\
\hline 2 & 183701 & Copenhagen Market 86 & ITA & Round & $\mathrm{G}$ & G & 31.1 & 32.0 & 1830 & 1732 & 17.0 & 19.3 & 16.5 & 19.8 & 7.0 & 9.1 \\
\hline 3 & 189963 & Skvirskaya N32 & UKR & Round & BRG & $\mathrm{G}$ & 44.2 & 41.7 & 970 & 904 & 12.0 & 12.4 & 17.5 & 17.8 & 6.5 & 4.9 \\
\hline 4 & 189965 & Zavadovskaya & KAZ & Round & $\mathrm{G}$ & G & 66.0 & 43.8 & 1670 & 590 & 20.0 & 13.1 & 18.0 & 18.5 & 8.0 & 4.8 \\
\hline 5 & 203329 & Zavodovskaya & KAZ & Round & BRG & BRG & 40.3 & 24.0 & 850 & 508 & 13.6 & 11.0 & 14.3 & 11.9 & 5.1 & 3.9 \\
\hline 6 & 204326 & Nonkwawon-1998-3606 & UNK & Round & BRG & $\mathrm{G}$ & 33.0 & 26.0 & 1960 & 1476 & 17.0 & 16.0 & 18.0 & 18.5 & 6.5 & 7.8 \\
\hline 7 & 206819 & Kik-1998-6099 & UNK & Round & $\mathrm{G}$ & $\mathrm{G}$ & 29.0 & 23.0 & 940 & 674 & 16.0 & 12.5 & 12.0 & 12.5 & 4.5 & 6.5 \\
\hline 8 & 803361 & Zuun kharaa Nr 2 & MNG & Round & BRG & LG & 40.0 & 26.0 & 1535 & 488 & 17.1 & 11.3 & 16.2 & 11.3 & 6.2 & 4.6 \\
\hline 9 & 803365 & Zuun kharaa Nr 6 & MNG & Round & BRG & LG & 48.2 & 27.3 & 1515 & 366 & 16.8 & 12.2 & 16.2 & 11.8 & 8.2 & 4.2 \\
\hline 10 & 803368 & Zuun kharaa Nr 9 & MNG & Round & BRG & BRG & 44.0 & 29.1 & 1430 & 968 & 15.1 & 13.1 & 16.8 & 14.6 & 5.7 & 6.5 \\
\hline 11 & 803369 & Zuun kharaa Nr 10 & MNG & Round & BRG & $\mathrm{G}$ & 39.0 & 30.2 & 1065 & 850 & 13.6 & 11.5 & 14.7 & 13.2 & 6.2 & 5.5 \\
\hline 12 & 803370 & Zuun kharaa Nr 11 & MNG & Round & BRG & BRG & 48.0 & 25.8 & 1670 & 734 & 15.4 & 14.0 & 17.2 & 12.6 & 5.1 & 4.8 \\
\hline 13 & 803375 & Zuun kharaa Nr 16 & MNG & Round & BRG & G & 43.0 & 28.7 & 1375 & 514 & 16.5 & 11.3 & 15.7 & 11.2 & 6.3 & 4.8 \\
\hline 14 & 803377 & Zuun kharaa Nr 18 & MNG & Round & $\mathrm{G}$ & BRG & 50.1 & 23.1 & 1610 & 668 & 17.1 & 12.3 & 18.2 & 13.6 & 6.8 & 4.2 \\
\hline 15 & 906763 & Kenkei YR 21 & NA & Round & DG & $\mathrm{G}$ & 34.0 & 27.8 & 1460 & 762 & 16.0 & 12.4 & 16.0 & 14.6 & 6.5 & 4.1 \\
\hline 16 & 906764 & Natsuzoka & NA & Round & BRG & G & 44.3 & 29.0 & 1280 & 1164 & 12.4 & 11.4 & 18.4 & 18.2 & 5.1 & 5.3 \\
\hline 17 & 906766 & Ohzora & JPN & Round & BRG & $\mathrm{G}$ & 43.0 & 32.0 & 1225 & 1268 & 13.9 & 12.5 & 16.8 & 17.6 & 4.4 & 5.0 \\
\hline 18 & 906777 & Uji Nr 1 & NA & Semi-F & $\mathrm{G}$ & $\mathrm{G}$ & 46.0 & 34.3 & 1490 & 992 & 13.5 & 11.3 & 18.5 & 15.5 & 5.4 & 3.6 \\
\hline 19 & 908150 & BOL-AWS-1999-154 & NA & Pointed & BRG & DG & 32.0 & 29.5 & 1160 & 980 & 20.0 & 18.3 & 14.0 & 12.6 & 8.0 & 6.5 \\
\hline 20 & 908775 & Taskaram & UZB & Round & LG & LG & 55.0 & 32.3 & 960 & 872 & 14.8 & 13.5 & 14.7 & 16.0 & 5.2 & 5.6 \\
\hline 21 & 908777 & Beloko chanaya & UZB & Semi-F & LG & LG & 55.0 & 28.6 & 1435 & 1208 & 14.6 & 14.1 & 18.2 & 18.4 & 8.5 & 5.5 \\
\hline 22 & K004495 & WIR1855 & NA & Round & BRG & BRG & 23.0 & 21.3 & 440 & 848 & 11.0 & 13.4 & 11.0 & 13.8 & 4.0 & 7.4 \\
\hline 23 & K004497 & $\begin{array}{l}\text { Derbentskaya Mestnaya } \\
\text { Uluchshennaya } 23\end{array}$ & RUS & Round & G & $\mathrm{G}$ & 30.6 & 22.1 & 910 & 1634 & 17.0 & 17.3 & 16.0 & 13.2 & 6.0 & 6.2 \\
\hline 24 & K004500 & WIR 2590 & NA & Semi-R & G & G & 40.0 & 29.8 & 1990 & 576 & 17.0 & 14.2 & 20.0 & 15.6 & 9.0 & 6.2 \\
\hline 25 & K004515 & $\begin{array}{l}\text { Nomer Pervyipolyarnyi } \\
\text { K-206 }\end{array}$ & RUS & Round & BRG & LG & 32.5 & 27.3 & 750 & 656 & 13.0 & 13.0 & 12.5 & 13.4 & 6.0 & 4.6 \\
\hline 26 & K004523 & Skorospelaya & RUS & Round & LG & LG & 27.0 & 17.1 & 750 & 532 & 12.5 & 12.1 & 15.0 & 11.5 & 4.0 & 4.5 \\
\hline 27 & K004524 & Losinoostrovskaya & RUS & Round & BRG & G & 41.0 & 38.1 & 1625 & 738 & 15.7 & 13.0 & 16.8 & 15.3 & 7.6 & 5.0 \\
\hline 28 & K004526 & Sudiya-146 & RUS & Semi-F & BRG & BRG & 47.0 & 41.7 & 2265 & 1080 & 17.2 & 14.2 & 23.3 & 17.9 & 10.4 & 5.2 \\
\hline 29 & K004535 & Slava 1305 & RUS & Round & $\mathrm{G}$ & $\mathrm{G}$ & 45.0 & 30.6 & 1935 & 898 & 18.2 & 14.0 & 17.4 & 15.1 & 7.8 & 5.4 \\
\hline 30 & K004536 & Nadezhda & RUS & Semi-F & LG & $\mathrm{G}$ & 53.0 & 45.2 & 1255 & 1050 & 14.9 & 13.6 & 17.1 & 16.4 & 6.1 & 5.3 \\
\hline 31 & K004538 & Iyunskaya & RUS & Round & LG & $\mathrm{LG}$ & 30.3 & 21.4 & 1210 & 738 & 16.5 & 13.8 & 13.5 & 12.4 & 8.0 & 5.8 \\
\hline 32 & K004542 & Slava 1305 & RUS & Round & BRG & G & 52.0 & 28.7 & 1105 & 678 & 15.3 & 11.7 & 14.8 & 13.7 & 6.5 & 4.4 \\
\hline 33 & K005289 & Dregonbul & NA & Round & $\mathrm{G}$ & $\mathrm{G}$ & 31.0 & 18.0 & 1500 & 180 & 15.0 & 9.0 & 16.0 & 8.0 & 6.5 & 2.5 \\
\hline 34 & K014433 & $\mathrm{Nr} 1$ & MNG & Round & $\mathrm{G}$ & $\mathrm{G}$ & 39.6 & 24.6 & 800 & 674 & 13.6 & 14.5 & 12.8 & 13.2 & 6.5 & 6.4 \\
\hline 35 & K014955 & CHN-MKH-2001-139 & NA & Round & $\mathrm{G}$ & $\mathrm{G}$ & 29.0 & 24.0 & 1300 & 598 & 15.0 & 11.0 & 15.5 & 12.3 & 6.0 & 4.0 \\
\hline 36 & K044570 & NPL-GYS-2004-26 & NPL & Round & BRG & BRG & 33.0 & 23.1 & 710 & 562 & 12.5 & 13.9 & 13.0 & 10.8 & 4.5 & 4.8 \\
\hline 37 & K100196 & Predzvest & NA & Round & $\mathrm{G}$ & $\mathrm{G}$ & 28.0 & 19.8 & 1280 & 306 & 18.0 & 12.2 & 17.0 & 10.3 & 8.5 & 4.3 \\
\hline 38 & K100197 & Pourovo cervene & NA & Round & PG & $\mathrm{P}$ & 53.5 & 32.5 & 960 & 391 & 15.7 & 12.5 & 12.8 & 12.2 & 6.4 & 5.8 \\
\hline 39 & K121377 & UZB-KJG-2006-37 & KGZ & Round & $\mathrm{BRG}$ & LG & 46.0 & 30.3 & 830 & 914 & 12.8 & 12.8 & 14.2 & 17.4 & 8.3 & 4.5 \\
\hline 40 & K125498 & Paz. Podobr & NA & Round & PG & PG & 50.2 & 38.7 & 1080 & 916 & 14.4 & 12.1 & 16.5 & 19.2 & 5.8 & 3.6 \\
\hline 41 & K125499 & Kose 27 & NA & Round & DG & LG & 43.0 & 28.4 & 1285 & 468 & 15.1 & 12.8 & 16.4 & 15.0 & 9.1 & 3.1 \\
\hline 42 & K134260 & HA15 & TUR & Round & PG & $\mathrm{P}$ & 48.7 & 38.1 & 720 & 224 & 12.5 & 9.8 & 11.0 & 8.1 & 8.5 & 3.1 \\
\hline 43 & K134820 & $\begin{array}{l}\text { Pazardzhishko } \\
\text { podobreno } 16\end{array}$ & BGR & Round & $\mathrm{P}$ & $\mathrm{P}$ & 50.0 & 50.5 & 1140 & 796 & 14.5 & 12.9 & 16.2 & 17.5 & 6.1 & 3.1 \\
\hline 44 & K136870 & Kyuse (bold) & BGR & Flat & BRG & BRG & 56.0 & 53.0 & 1750 & 520 & 15.0 & 10.8 & 19.5 & 14.0 & 8.5 & 4.0 \\
\hline 45 & K139318 & Okhina & NA & Semi-F & BRG & G & 34.0 & 27.0 & 2730 & 546 & 17.5 & 10.5 & 22.0 & 16.3 & 6.0 & 4.3 \\
\hline 46 & K142931 & Sudya & KGZ & Round & BRG & BRG & 32.3 & 35.1 & 890 & 926 & 13.0 & 11.5 & 16.0 & 19.2 & 8.0 & 4.3 \\
\hline 47 & K146556 & A8E0243 & BGR & Round & BRG & $\mathrm{G}$ & 46.0 & 37.4 & 1715 & 538 & 17.1 & 11.4 & 17.4 & 13.6 & 5.5 & 4.1 \\
\hline 48 & K154726 & Akimakigokuwase & JPN & R-P & G & LG & 37.0 & 25.3 & 1430 & 866 & 16.0 & 10.2 & 20.0 & 14.8 & 7.5 & 3.9 \\
\hline 49 & K155067 & UZB-GJG-2009-10/3-09 & $\mathrm{NA}$ & Round & LG & LG & 46.2 & 28.5 & 1590 & 1602 & 15.4 & 14.5 & 19.3 & 20.5 & 9.2 & 8.1 \\
\hline 50 & K155659 & CT-99 & KOR & Round & G & G & 29.0 & 25.0 & 1060 & 860 & 14.0 & 10.0 & 16.0 & 10.4 & 6.0 & 3.8 \\
\hline 51 & K155662 & CT-115 & KOR & Round & DG & $\mathrm{G}$ & 34.0 & 23.5 & 1300 & 1306 & 16.0 & 11.0 & 14.0 & 8.8 & 5.0 & 3.7 \\
\hline 52 & K155664 & CT-117 & KOR & Round & DG & $\mathrm{G}$ & 39.8 & 24.8 & 1545 & 810 & 16.6 & 12.9 & 15.2 & 13.9 & 5.7 & 4.9 \\
\hline 53 & K164144 & CHN-AWS-2010-12 & $\mathrm{CHN}$ & Round & G & G & 26.0 & 19.6 & 1090 & 990 & 14.5 & 11.3 & 14.0 & 11.4 & 3.5 & 4.6 \\
\hline 54 & K166200 & 1740 & KOR & Round & BRG & BRG & 42.2 & 33.5 & 475 & 404 & 9.2 & 9.0 & 11.3 & 12.9 & 4.2 & 2.6 \\
\hline 55 & K166205 & 153 & KOR & Round & DG & $\mathrm{G}$ & 41.5 & 30.7 & 1000 & 176 & 15.0 & 9.7 & 14.0 & 10.0 & 6.0 & 2.0 \\
\hline 56 & K166237 & Doberrot & DEU & Round & PG & $\mathrm{P}$ & 33.0 & 21.0 & 670 & 398 & 13.1 & 9.8 & 10.2 & 8.8 & 5.3 & 3.2 \\
\hline
\end{tabular}


Continuation Table 1.

\begin{tabular}{|c|c|c|c|c|c|c|c|c|c|c|c|c|c|c|c|c|}
\hline \multirow[b]{2}{*}{$\mathrm{SN}$} & \multirow[b]{2}{*}{ Number } & \multirow[b]{2}{*}{ Resource name } & \multirow[b]{2}{*}{ Origin $^{1}$} & \multirow{2}{*}{$\begin{array}{l}\text { Head } \\
\text { shape }\end{array}$} & \multirow{2}{*}{$\begin{array}{l}\text { Outer } \\
\text { leaf } \\
\text { color }\end{array}$} & \multirow{2}{*}{$\begin{array}{l}\text { Inner } \\
\text { leaf } \\
\text { color }\end{array}$} & \multicolumn{2}{|c|}{ Leaf length } & \multicolumn{2}{|c|}{ Head weight } & \multicolumn{2}{|c|}{ Head height } & \multicolumn{2}{|c|}{ Head width } & \multicolumn{2}{|c|}{ Core length } \\
\hline & & & & & & & \multicolumn{2}{|c|}{ Spring Autumn } & $\mathrm{NP}$ & Autur & of & ttu & Spring & utun & ing & tur \\
\hline & & & & & & & - & $\mathrm{m}-$ & - & $\mathrm{g}-$ & $-\mathrm{c}$ & $\mathrm{m}-$ & $-\mathrm{c}$ & $n-$ & - & $n$ \\
\hline 57 & K166240 & Red Drumhead 2 & SWE & Round & PG & PG & 43.0 & 22.9 & 490 & 128 & 12.5 & 7.4 & 10.2 & 6.8 & 4.4 & 3.1 \\
\hline 58 & K175584 & 213 & KOR & Round & $\mathrm{G}$ & G & 33.5 & 21.6 & 1260 & 1028 & 15.5 & 12.8 & 14.0 & 12.6 & 5.5 & 4.1 \\
\hline 59 & K176590 & $\begin{array}{l}\text { Da shanghai xin zheng } \\
\text { chin ganlan }\end{array}$ & $\mathrm{CHN}$ & Round & G & G & 41.0 & 25.6 & 2160 & 1560 & 20.0 & 16.5 & 17.0 & 15.2 & 5.0 & 4.4 \\
\hline 60 & K176592 & Qing Feng & $\mathrm{CHN}$ & Round & BRG & BRG & 40.2 & 29.8 & 2330 & 1150 & 19.0 & 14.6 & 19.5 & 18.7 & 5.5 & 5.1 \\
\hline 61 & K176593 & Zhong & CHN & Round & G & G & 29.0 & 24.5 & 1240 & 644 & 16.5 & 12.0 & 17.0 & 13.5 & 5.5 & 4.0 \\
\hline 62 & K176594 & Zao Hong & CHN & Round & $P$ & $\mathrm{P}$ & 30.5 & 20.1 & 2430 & 624 & 18.0 & 12.2 & 17.5 & 10.8 & 12.0 & 4.8 \\
\hline 63 & K176595 & Zhong & CHN & Round & G & G & & 28 & 1250 & 924 & 15 & 14.0 & 16 & 14.5 & te. & 6.0 \\
\hline 64 & K195951 & Golc & & & G & G & & & & 248 & & 9.5 & & 9.5 & 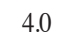 & 4.0 \\
\hline 65 & K204466 & CT-2 & & Round & G & G & & & & 554 & & 12.1 & 1 & 12.7 & 0 & 3.8 \\
\hline 66 & K222934 & $\mathrm{CH} \&$ & & Round & BRG & BRG & 32 & 29.1 & 980 & 428 & 14 & 11.1 & & 10.6 & 6.1 & 3.4 \\
\hline 67 & K243819 & Miya Bi & HA & Round & G & G & 42.0 & 29.2 & 1865 & 1116 & 14.4 & 11.3 & 19.2 & 18.0 & 8.1 & 4.9 \\
\hline 68 & K246353 & $90 \mathrm{~ms}$ & OR & Round & BRG & BRG & 34.0 & 26.9 & 1140 & 668 & 15.8 & 13.6 & 13.6 & 13.7 & 7.2 & 3.5 \\
\hline 69 & K246359 & P15-41 & KOR & Round & $\mathrm{G}$ & G & 29.9 & 18.7 & 1265 & 354 & 14.5 & 18.1 & 15.7 & 13.0 & 5.4 & 3.0 \\
\hline 70 & K246894 & $\begin{array}{l}\text { Succession Green } \\
\text { Leaved }\end{array}$ & ARM & Flat & BRG & BRG & 45.0 & 30.0 & 750 & 502 & 10.3 & 10.3 & 16.8 & 17.0 & 6.4 & 4.5 \\
\hline 71 & K246 & A5-7 & & & BRG & G & & & 10 & & & & & 15.9 & & 4.3 \\
\hline 72 & K247130 & N 127 & & Round & G & G & 39.0 & 29. & 830 & 676 & 14 & 13.5 & 13.5 & 14.3 & 0.0 & 4.6 \\
\hline 73 & K247132 & Mihnev & RUS & Round & PG & PG & 34.0 & 29.5 & 1750 & 544 & 14 & 12.2 & 13.1 & 10.5 & .7 & 5.6 \\
\hline 74 & K247741 & TJK-PH & TJK & Round & BRG & BRG & 43.0 & 28.8 & 1125 & 606 & 14.9 & 11.2 & 15.6 & 14.2 & 5.2 & 3.3 \\
\hline 75 & K247794 & Apsheronskaya & TJK & Round & G & $\mathrm{G}$ & 47.3 & 35.6 & 910 & 680 & 17.2 & 15.2 & 13.8 & 12.6 & 4.2 & 4.0 \\
\hline
\end{tabular}

'Alpha-3 country code.

Bold numbers are official introductory numbers, and the other numbers are temporary accession numbers; NA: no information available; R-P: round and pointed; Semi-F: semi-flat; Semi-R: semi-round; BRG: bright green; G: green; DG: dark green; LG: light green; PG: purple green, P: purple.

Figure 1. Changes in air temperature, air humidity, cumulative radiation, and rainfall at the experimental field in spring (A and $C$ ) and autumn (B and D). Horizontal dotted lines indicate average values.
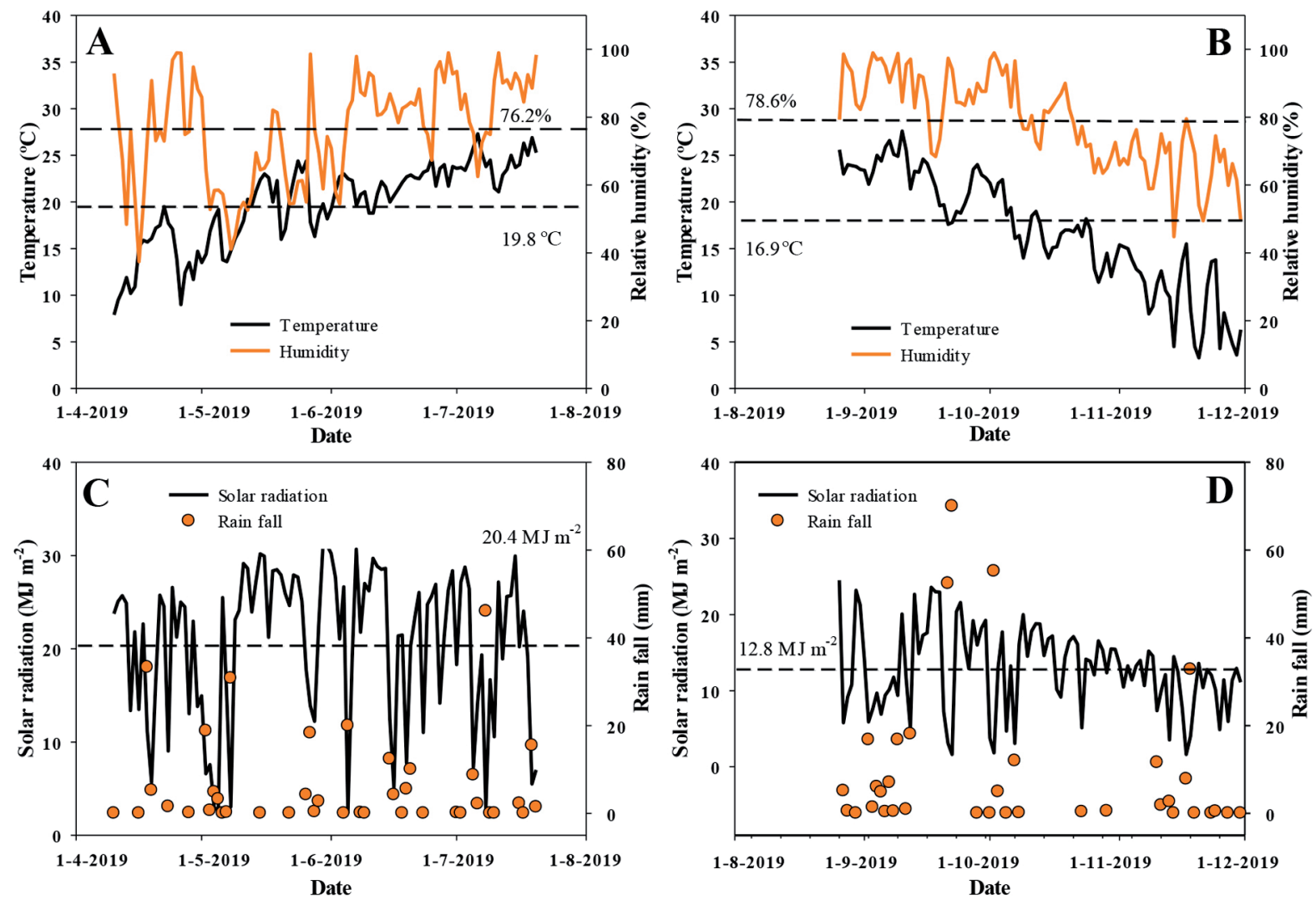


\section{Sugar content and sweetness analysis}

Sugar content was analyzed according to the method described by Bhandari and Kwak (2015a) with some modifications. Sugar was extracted from powdered cabbage samples $(0.2 \mathrm{~g})$ with distilled water $(5.0 \mathrm{~mL})$ in a water bath at $80{ }^{\circ} \mathrm{C}$ under shaking at $150 \mathrm{rpm}$ for $20 \mathrm{~min}$. The samples were immediately cooled, centrifuged at $3500 \mathrm{rpm}$ for $10 \mathrm{~min}$, and filtered through a $0.22 \mu \mathrm{m}$ syringe filter. The filtrate was analyzed with a 1260 HPLC system (Agilent Technologies, Santa Clara, California, USA) equipped with a quaternary HPLC pump, an auto-sampler, and a refractive index detector. The separation of sugars was performed with a carbohydrate analysis column $(4.6 \times 250 \mathrm{~mm}, 5 \mu \mathrm{m}$; ZORBAX, Agilent Technologies $)$ protected by a guard column and at a column oven temperature of $30{ }^{\circ} \mathrm{C}$. Acetonitrile/distilled water $(75 / 25, \mathrm{v} / \mathrm{v})$ at a flow rate of $1.4 \mathrm{~mL} \mathrm{~min}^{-1}$ was used as the mobile phase. Individual sugar peaks were identified and quantified based on retention times and peak areas compared with authentic standards. Authentic standards of glucose, fructose, and sucrose were obtained from Sigma-Aldrich (St. Louis, Missouri, USA). All analyses were performed in triplicate and results were expressed as $\mathrm{mg} \mathrm{g}^{-1}$ dry weight (DW).

The total sweetness index (TSI) was calculated using concentration and the sweetness coefficient of each sugar according to Magwaza and Opara (2015).

\section{Statistical analyses}

Means of three replicates were used for statistical analyses. Data were analyzed with SPSS Statistics 20.0 (IBM, Armonk, New York, USA). Effects of cultivar, growing season, and their interaction were analyzed by fitting a mixed model one-way ANOVA. Correlations were tested using Pearson's correlation coefficient ( $r$ ) at $p \leq 0.05$. All the figures were computed with SigmaPlot 12.0 (Systat Software Inc., San Jose, California, USA).

\section{RESULTS AND DISCUSSION}

\section{Variation in agronomic characteristics}

Qualitative and quantitative agronomic parameters were measured during and after harvest. Qualitative parameters such as head shape and outer and inner leaf color were only recorded in spring, while the quantitative agronomic parameters were recorded in both seasons. Six categories of head shapes were identified as round, flat, semi-flat, pointed, semi-round, and round-pointed; most genotypes $(\mathrm{n}=64)$ showed a round head shape (Table 1). Similar cabbage head shapes were observed in previous studies (Cervenski et al., 2010; De Mortel, 2018). Cabbage genotypes also showed considerable variability in outer and inner leaf color, which was classified in six categories of bright green, green, dark green, light green, purple green, and purple. Outer leaves were bright green in 31 genotypes and green in 25 genotypes (Figure 2). In contrast, inner leaves were green in most genotypes $(n=38)$, followed by bright green $(n=17)$. Eight genotypes belonged to the red cabbage category because they had purple/purple green outer and inner leaves, depending on genotype. Detailed information on agronomic characteristics of each genotype is displayed in Table 1 . The quantitative parameters evaluated in the present study included leaf length, head weight, head height, head width, and core length, which also exhibited variability across genotypes. All of these parameters showed higher mean values in spring than in autumn, and variation expressed as coefficients of variation was higher in autumn than in spring (Table 2). Mean leaf length, head height, head width, and core length were $39.4,15.1,15.8$, and $6.4 \mathrm{~cm}$, respectively, in spring and 28.7, 14.5, 16.7, and $25.3 \mathrm{~cm}$ in autumn with a coefficient of variation of $23.7 \%, 17.0 \%, 24.3 \%$, and $27.6 \%$, respectively.

Among the quantitative agronomic parameters, head weight exhibited the largest variation in spring (36.9\%) and autumn (49.2\%). Substantial genotypic variation associated with quantitative parameters was previously observed in different crops, including cabbage (Balkaya et al., 2005; Weerakoon and Somaratne, 2011; El-Esawi et al., 2012; Kibar et al., 2016; Garcia-Diaz et al., 2018; Ribeiro et al., 2019). However, this is the first report describing seasonal variation in morphological characteristics of different cabbage genotypes from different origins. Our results suggest that overall fluctuations in agronomic parameters are mostly due to plant genotypes and different climatic conditions between spring and autumn. 
Figure 2. Frequencies of genotypes of different outer and inner cabbage leaf color.

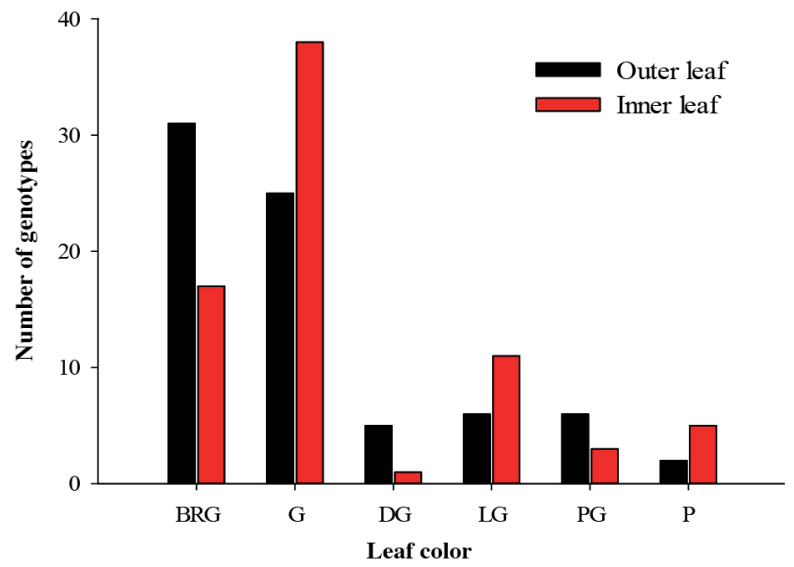

BRG: Bright green; G: green; DG: dark green; LG: light green; PG: purple green, P: purple.

Table 2. Agronomic characteristics of 75 cabbage genotypes grown in two seasons.

\begin{tabular}{|c|c|c|c|c|c|c|}
\hline \multirow[b]{2}{*}{ Variables } & \multicolumn{2}{|c|}{ Range } & \multicolumn{2}{|c|}{ Average } & \multicolumn{2}{|c|}{$\mathrm{CV}(\%)$} \\
\hline & Spring & Autumn & Spring & Autumn & Spring & Autumn \\
\hline Leaf length, cm & $22.0-66.0$ & $16.0-50.5$ & 39.4 & 28.6 & 22.4 & 23.5 \\
\hline Head weight, $g$ & $440.0-2730.0$ & $128.0-2124.0$ & 1282.7 & 777.8 & 36.9 & 49.2 \\
\hline Head height, $\mathrm{cm}$ & $9.2-20.0$ & 7.4-19.3 & 15.1 & 12.6 & 14.5 & 17.0 \\
\hline Head width, cm & $10.2-23.3$ & $6.8-27.0$ & 15.8 & 14.1 & 16.7 & 24.3 \\
\hline Core length, $\mathrm{cm}$ & $3.5-12.0$ & $2.0-9.1$ & 6.4 & 4.7 & 25.3 & 27.6 \\
\hline
\end{tabular}

CV: Coefficient of variation.

\section{Variation in free sugar concentrations and total sweetness index (TSI)}

The concentrations of the three sugars, glucose, fructose, and sucrose, in cabbage head germplasm during spring and autumn 2019 are shown in Figure 3. Fructose and glucose were the predominant sugars in cabbage germplasm, which concurred with findings from previous studies on cabbage (Rosa et al., 2001; Zhao et al., 2020) and other brassicaceous vegetables such as broccoli and cauliflower (Bhandari and Kwak, 2015a; 2015b). In most cases, the germplasm content of glucose was the highest, followed by fructose and sucrose in both growing seasons.

The mean glucose content in spring was $209.3 \mathrm{mg} \mathrm{g}^{-1}$, which varied between 126.5 and $276.7 \mathrm{mg} \mathrm{g}^{-1}$ dry weight, whereas it ranged from 115.8 to $272.1 \mathrm{mg} \mathrm{g}^{-1}$ in autumn with a mean of $214.9 \mathrm{mg} \mathrm{g}^{-1}$. However, genotypic variation as measured by the coefficient of variation was similar across seasons (approximately $15 \%$, Table 3 ). The proportion of glucose in the total free sugar content was higher in spring $(55.0 \%)$ than in autumn (48.6\%, Figure 4). Glucose represented the highest sugar proportion in spring in all genotypes, but only in approximately $75 \%$ of all genotypes in autumn. Approximately 33\% of the genotypes showed higher glucose content in spring than in autumn, whereas the other genotypes showed either higher or similar glucose content in autumn. Bhandari and Kwak (2015a) found higher glucose content in spring than in autumn in 12 broccoli cultivars. Similarly, Rosa et al. (2001) observed higher glucose content in cabbage grown in spring than in autumn. Effects of genotype and growing season on other bioactive compounds have been previously observed (Cartea et al., 2008; Choi et al., 2014; Bhandari et al., 2020), suggesting that the accumulation of phytochemicals in vegetables depends on plant species and on the nature of phytochemicals. Furthermore, we found a differential accumulation of glucose content that depended on the genotype. Further studies on molecular genetics are required to elucidate genotype-dependent seasonal variation in sugar content. Five genotypes (183701, K176592, K246359, K154726, and 906763) showed higher glucose concentrations (> $250.0 \mathrm{mg} \mathrm{g}^{-1} \mathrm{DW}$ ) in spring, whereas genotypes 160330, K044570, K004538, K176595, K176593, K121377, and K176592 showed higher glucose concentrations (> $250 \mathrm{mg} \mathrm{g}^{-1} \mathrm{DW}$ ) in autumn (Figure 3). 
Figure 3. Seasonal variation in fructose (A), glucose (B), and sucrose (C) concentrations in 75 cabbage genotypes. Refer to Table 1 for detailed information on genotypes.
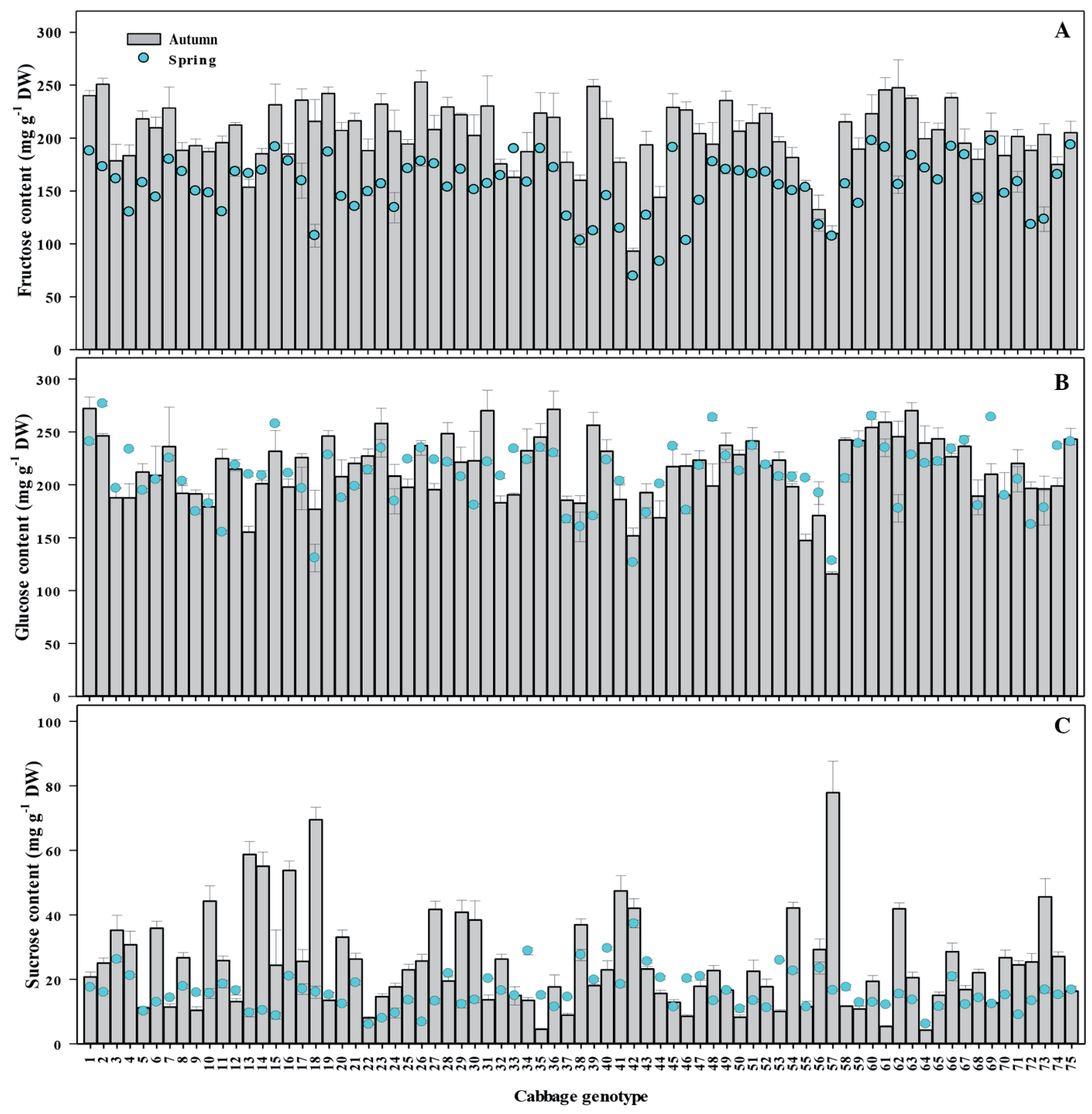

Bars indicate the mean \pm standard deviation of three replicates. 
Table 3. Free sugar content and total sweetness index (TSI) in cabbage genotypes $(n=75)$ grown in two seasons.

\begin{tabular}{lcccc}
\hline Season & Sugar & Average & Range & CV \\
\hline \multirow{4}{*}{ Spring } & & $\mathrm{mg} \mathrm{g}^{-1}$ & $\mathrm{mg} \mathrm{g}^{-1}$ & $\%$ \\
& Fructose & 155.3 & $69.5-197.6$ & 17.8 \\
& Glucose & 209.3 & $126.5-276.7$ & 14.8 \\
& Sucrose & 16.0 & $6.0-37.2$ & 36.0 \\
& Total sugar & 380.5 & $233.1-475.3$ & 14.0 \\
& TSI & 407.9 & $237.5-510.5$ & 14.6 \\
\hline \multirow{4}{*}{ Autumn } & Fructose & 202.1 & $93.2-253.0$ & 15.4 \\
& Glucose & 214.9 & $115.8-272.1$ & 14.6 \\
& Sucrose & 24.7 & $4.2-77.9$ & 60.5 \\
& Total sugar & 441.7 & $286.9-534.8$ & 12.3 \\
& TSI & 491.2 & $297.1-599.7$ & 12.7 \\
\hline
\end{tabular}

CV: Coefficient of variation.

Figure 4. Average proportions of fructose, glucose, and sucrose in total sugar content in spring (A) and autumn (B).

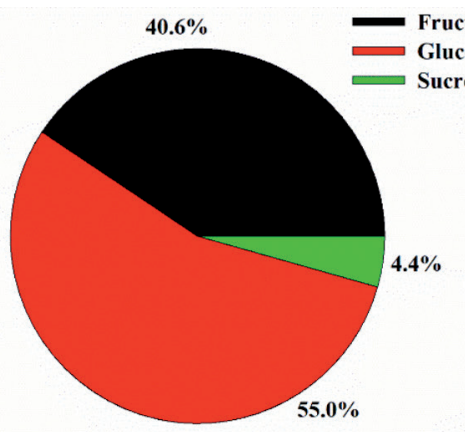

A

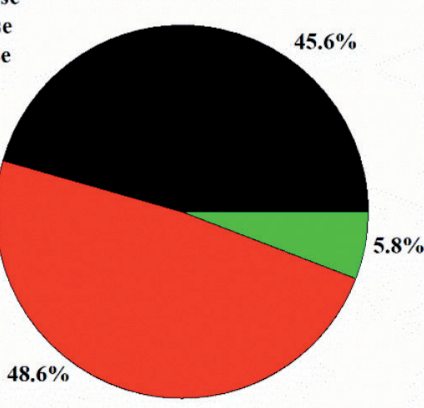

B

Fructose, which was also abundant, showed significant variations among genotypes in both seasons with some reverse accumulation between seasons when compared to glucose. Most genotypes showed higher fructose content in autumn than in spring (Figure 3) ranging from 69.5 to $197.6 \mathrm{mg} \mathrm{g}^{-1}$ in spring and from 93.2 to $253.3 \mathrm{mg} \mathrm{g}^{-1}$ in autumn. Mean fructose concentrations were higher in autumn $\left(202.1 \mathrm{mg} \mathrm{g}^{-1}\right)$ than in spring $\left(155.3 \mathrm{mg} \mathrm{g}^{-1}\right.$, Table 3$)$. The concentrations observed in the present study were higher than those previously reported (Rosa et al., 2001); this could be due to differences in genotypes and environmental conditions. The proportion of fructose was higher in autumn (45.6\%) than in spring (40.6\%, Figure 4), but genotypic variation was slightly lower in autumn than in spring. Higher fructose concentrations in autumn increased the sweetness of cabbage because fructose is the predominant contributor to sweetness and can mask bitter taste, thereby increasing palatability (Schonhof et al., 2004; Joesten et al., 2007).

In some genotypes $(n=18)$, fructose was higher in autumn. The proportions of glucose were typically lower in autumn than in spring; however, these proportions were higher in both seasons compared to fructose. Our results are consistent with the results reported by Rosa et al. (2001), who found higher fructose concentrations in autumn than in spring. Seven genotypes showed higher fructose concentrations (> $\left.190 \mathrm{mg} \mathrm{g}^{-1} \mathrm{DW}\right)$ in spring, whereas 50 genotypes produced higher fructose concentrations (> $190 \mathrm{mg} \mathrm{g}^{-1} \mathrm{DW}$ ) in autumn. Three genotypes (K222934, K176593, and 906763) produced relatively high and stable fructose concentrations in both seasons.

Sucrose content showed substantial changes and produced considerable genotypic variation (Figure 3). In spring, sucrose showed more than six-fold variation, ranging from 6.0 to $37.2 \mathrm{mg} \mathrm{g}^{-1}$ with a mean concentration of $16.0 \mathrm{mg} \mathrm{g}^{-1}$. This range was wider in autumn than in spring, with about 18 -fold variation between highest and lowest values. The average sucrose content in autumn was $24.7 \mathrm{mg} \mathrm{g}^{-1}$ which was higher than that observed during spring. The variation as measured by the coefficient of variation was higher in autumn $(60.5 \%)$ than in spring (36.0\%; Table 3$)$. The proportion of sucrose was higher in autumn (5.8\%) than in spring (4.4\%; Figure 4), which was probably due to higher fluctuation in climatic factors (Figure 1) as sucrose is a compatible solute that accumulates during stress conditions (Serraj and Sinclair, 2002). Furthermore, acid invertase activity may be lower in autumn than in spring which would cause an increase in the 
proportion of sucrose (Sung et al., 1994). Seven genotypes produced higher sucrose concentrations $\left(>25.0 \mathrm{mg} \mathrm{g}^{-1}\right)$ in spring and 31 genotypes in autumn.

Total sugar concentrations in spring ranged from 233.1 to $475.3 \mathrm{mg} \mathrm{g}^{-1}$ with a mean concentration of $380.5 \mathrm{mg} \mathrm{g}^{-1}$. Total sugar concentrations were higher in autumn (286.9-534.8 $\mathrm{mg} \mathrm{g}^{-1}$ ), with an average value of $441.7 \mathrm{mg} \mathrm{g}^{-1}$ (Figure 5, Table 3). Lower sugar content in spring was probably due to increased photorespiration under higher temperatures which likely reduced photosynthetic efficiency (Nilsen and Orcutt, 1996). Overall variation was lower in autumn (12.3\%) than in spring (14.0\%). Genotypes namely 160330 (Nr 1), 183701 (Nr 2), 906763 (Nr 15), K154726 (Nr 48), K176592 ( $\mathrm{Nr}$ 60), K222937 ( $\mathrm{Nr} 66$ ), K246359 ( $\mathrm{Nr} 69$ ), and K247794 ( $\mathrm{Nr} 75$ ) belonged to upper $10 \%$ of the total genotypes with higher total sugar concentrations ( $\left.>445.0 \mathrm{mg} \mathrm{g}^{-1}\right)$ in spring, while the upper $10 \%$ of the total genotypes exhibited total sugar concentration higher than $510.0 \mathrm{mg} \mathrm{g}^{-1}$ in autumn. Only two genotypes; 160330 and 183701 exhibited relatively high and stable total sugar content belonging to the upper $10 \%$ of the genotypes in both seasons.

One of the commonly used sweetness indexes to indicate the sweetness of horticultural crops, TSI, exhibited different values depending upon the genotypes and seasons (Figure 5). Average TSI was about 25\% higher in autumn compared to spring although quite similar genotypic variation was found in both the seasons (Table 3). Similar to the fructose and total sugar concentration, almost of the genotypes showed higher TSI in autumn than in spring (Figure 5). Similar genotypes as in the total sugar concentration also belonged to the upper $10 \%$ of the total genotypes with the higher TSI in both spring and autumn as a result only two genotypes 160330 and 183701 showed relatively stable and higher TSI in both seasons. As TSI has been considered more suitable parameter compared to the other sweetness indices for the prediction of overall acceptability in vegetables (Magwaza and Opara, 2015), the results along with total sugar concentration might be useful for the selection of high sweetness cabbage genotypes.

Figure 5. Seasonal variation in total free sugar content $(A)$ and total sweetness index $(B)$ in 75 cabbage genotypes. Refer to Table 1 for detailed information on genotypes.

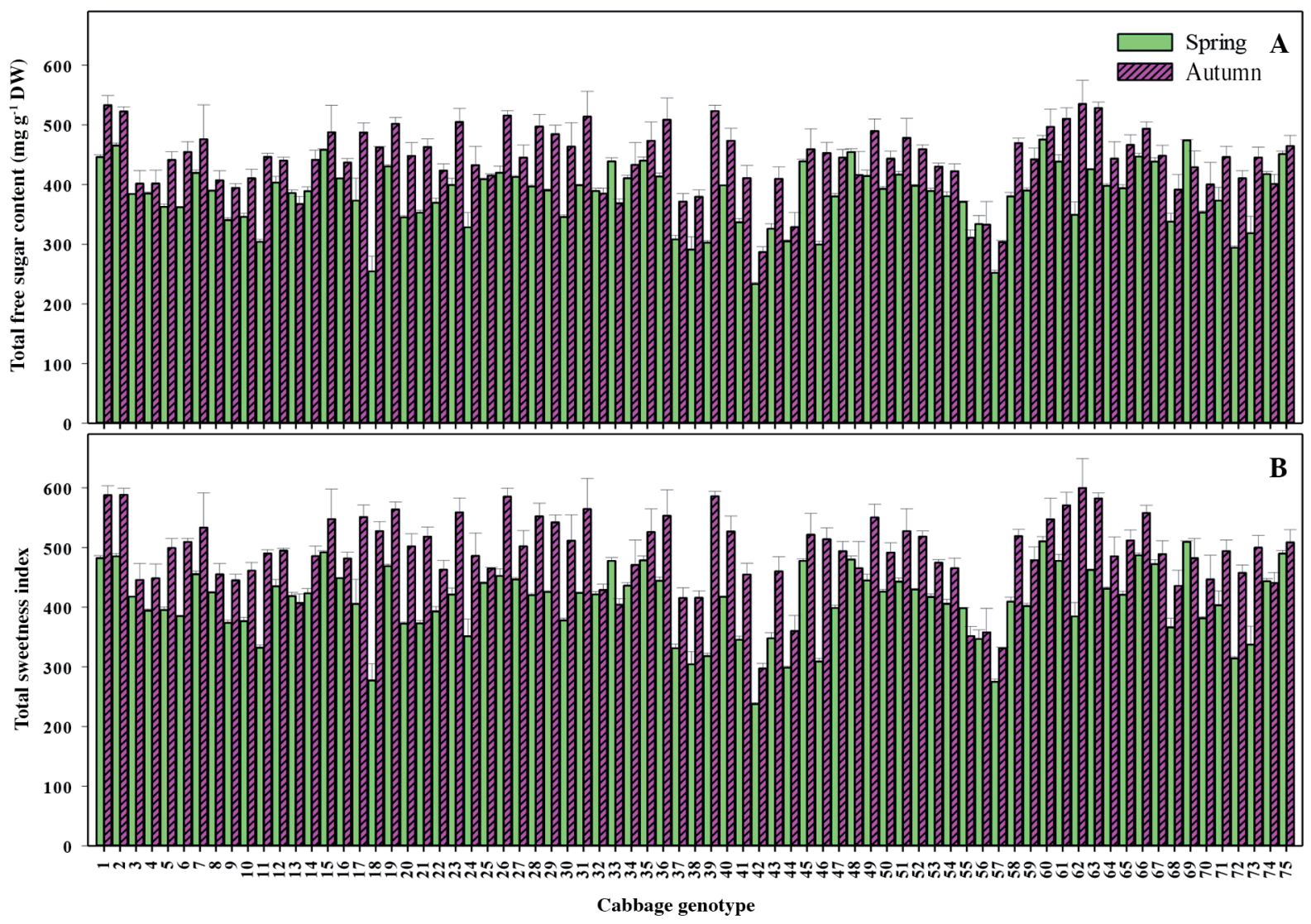

Bars indicate means \pm standard deviation of three replicates. 
Taken together, our study showed significant effects of cabbage genotypes and environmental conditions on the composition of sugars. We also found significant genotypic variation in glucosinolate concentrations in a different study (Bhandari et al., 2020). To the best of our knowledge, this is the first report on variation in sugar content in a large number of cabbage genotypes from diverse origins grown in two different seasons, as most previous studies used fewer genotypes and were limited to one season. Our results may be of use for selecting candidate cabbage genotypes for future breeding programs.

Our results also showed that free sugar content in cabbage heads is affected by genotype, growing season, and their interaction (Table 4), suggesting that free sugar in cabbage is markedly influenced by genetic and environmental factors. Similar results were previously reported by Rosa et al. (2001). Furthermore, genotype- and season-dependent variation have been reported in other phytochemicals of many brassicaceous vegetables (Aires et al., 2011; Bhandari and Kwak, 2014). However, the current study is the first to examine variation sugar concentrations in a large number of cabbage genotypes from different origins grown in different seasons. Production of high concentrations of sugars in selected genotypes may be of interest for selecting cabbage breeding material.

\section{Correlation analyses}

To test direction and magnitude of correlations between parameters, correlation analyses of quantitative agronomic characters and sugar content were performed. We observed significant positive correlations among quantitative agronomic parameters (Table 5) with the strongest positive correlation between cabbage head weight and head height $(\mathrm{r}=0.727 ; \mathrm{p}<0.01)$ and weakest positive correlation between leaf length and core length $(\mathrm{r}=0.347 ; \mathrm{p}<0.01)$, which is in line with results of previous studies (Cervenski et al., 2010; Singh et al., 2010; Adzic et al., 2012). Thus, selection based on these parameters either in combination or individually may help identify genotypes with potential for higher yields. Head height and width were strongly positively correlated with glucose content, whereas all other combinations of agronomic characters and individual sugar content produced either significantly negative or nonsignificant correlations, suggesting weak association of yield and sweetness. Only fructose and glucose showed a significant positive correlation with the strongest correlation between total sugar content and fructose $(r=0.947 ; p<0.01)$. Furthermore, fructose was significantly correlated with glucose $(r=0.684 ; \mathrm{p}<0.01)$. In contrast, sucrose concentration produced either significantly negative or nonsignificant correlations with other sugar and total sugar concentrations. However, sucrose showed significant negative correlations with concentrations of other sugars and total sugar content in spring and autumn (data not shown) suggesting general conversion of sucrose to glucose and fructose in spring.

Table 4. ANOVA of sugar concentrations and total sweetness index (TSI) in different cabbage genotypes.

\begin{tabular}{|c|c|c|c|c|c|c|c|c|c|c|}
\hline \multirow[b]{2}{*}{ Variables } & \multicolumn{2}{|c|}{ Fructose } & \multicolumn{2}{|c|}{ Glucose } & \multicolumn{2}{|c|}{ Sucrose } & \multicolumn{2}{|c|}{ Total sugar } & \multicolumn{2}{|r|}{ TSI } \\
\hline & F-value & Significance & F-value & Significance & F-value & Significance & F-value & Significance & F-value & Significance \\
\hline Genotype (G) & 47.9 & $* * *$ & 46.7 & $* * *$ & 113.7 & $* * *$ & 41.9 & $* * *$ & 45.2 & $* * *$ \\
\hline Season $(\mathrm{S})$ & 2980.8 & $* * *$ & 35.5 & $* * *$ & 2295.8 & $* * *$ & 1355.9 & $* * *$ & 2096.0 & $* * *$ \\
\hline $\mathrm{G} \times \mathrm{S}$ & 15.1 & $* * *$ & 13.5 & $* * *$ & 91.2 & $* * *$ & 13.9 & $* * *$ & 14.9 & $* * *$ \\
\hline
\end{tabular}

$* * *$ Significance at $\mathrm{p}<0.001$.

Table 5. Correlation coefficients in cabbage.

\begin{tabular}{|c|c|c|c|c|c|c|c|c|c|}
\hline Parameters & Leaf length & Head height & Head width & Core length & Fructose & Glucose & Sucrose & Total sugar & TSI \\
\hline Head weight & $0.407 * *$ & $0.727 * *$ & $0.723 * *$ & $0.590 * *$ & -0.095 & $0.270 * *$ & $-0.253 * *$ & 0.028 & 0.153 \\
\hline Leaf length & & $0.356 * *$ & $0.458 * *$ & $0.347 * *$ & $-0.511 * *$ & $-0.250 * *$ & -0.017 & $-0.440 * *$ & $-0.351 * *$ \\
\hline Head height & & & $0.470 * *$ & $0.593 * *$ & -0.081 & $0.283 * *$ & $-0.324 * *$ & 0.030 & 0.151 \\
\hline Head width & & & & $0.420 * *$ & 0.079 & $0.247 * *$ & -0.135 & 0.147 & $0.221 * *$ \\
\hline Core length & & & & & $-0.247 * *$ & 0.039 & $-0.168 *$ & $-0.164 *$ & -0.069 \\
\hline Fructose & & & & & & $0.684 * *$ & -0.039 & $0.947 * *$ & $0.892 * *$ \\
\hline Glucose & & & & & & & $-0.382 * *$ & $0.846^{* *} *$ & $0.891 * *$ \\
\hline Sucrose & & & & & & & & -0.020 & -0.121 \\
\hline Total sugar & & & & & & & & & $0.969 * *$ \\
\hline
\end{tabular}

*, **Significant at $\mathrm{p}<0.05$ and $\mathrm{p}<0.01$, respectively.

TSI: Total sweetness index. 


\section{CONCLUSIONS}

The cabbage genotypes showed variation in agronomic characteristics and sugar content. Information on variation in agronomic characteristics is useful for identifying candidate genotypes for breeding programs. Furthermore, we also found significant differences in the levels of individual and total free sugars in cabbage in relation to genotype and growing season. Most genotypes produced higher fructose concentrations in autumn than in spring. Sucrose showed the highest genotypic and seasonal variation among the free sugars. The genotypes 160330 and 183701 produced higher free sugar concentrations in both growing seasons, suggesting their superiority in terms of sugar content. The findings of this study may be of use for developing novel cabbage breeding lines with desirable agronomic characteristics and high free sugar concentrations.

\section{ACKNOWLEDGEMENTS}

This research was funded by the National Agrobiodiversity Center, National Institute of Agricultural Sciences, Rural Development Administration, Korea (Grant Number: PJ014255) and partly by research funds of Jeonbuk National University in 2020 .

\section{REFERENCES}

Adzic, S., Pavlovic, S., Jokanovic, M.B., Cvikic, D., Pavlovic, N., Zdravkovic, J., et al. 2012. Correlation of important agronomic characteristics and yield of medium late genotypes of head cabbage. Acta Horticulturae 960:159-164. doi:10.17660/ActaHortic.2012.960.22.

Aires, A., Fernandes, C., Carvalho, R., Bennett, R.N., Saavedra, M.J., and Rosa, E.A.S. 2011. Seasonal effects on bioactive compounds and antioxidant capacity of six economically important Brassica vegetables. Molecules 16:6816-6832. doi:10.3390/molecules16086816.

Auerswald, H., Schwarz, D., Kornelson, C., Krumbein, A., and Bruckner, B. 1999. Sensory analysis, sugar and acid content of tomato at different EC values of the nutrient solution. Scientia Horticulturae 82:227-242. doi:10.1016/S0304-4238(99)00058-8.

Balkaya, A., Yanmaz, R., Apaydin, A., and Kar, H. 2005. Morphological characterization of white head cabbage (Brassica oleracea var. capitata subvar. alba) genotypes in Turkey. New Zealand Journal of Crop and Horticultural Science 33:333341. doi:10.1080/01140671.2005.9514367.

Banerjee,A., Variyar,P.S.,Chatterjee,S., and Sharma,A.2014.Effect of post-harvest radiation processing and storage on the volatile oil composition and glucosinolate profile of cabbage. Food Chemistry 151:22-30. doi:10.1016/j.foodchem.2013.11.055.

Bhandari, S.R., and Kwak, J.H. 2014. Seasonal variation in phytochemicals and antioxidant activities in different tissues of various broccoli cultivars. African Journal of Biotechnology 13(4):604-615. doi:10.5897/AJB2013.13432.

Bhandari, S.R., and Kwak, J.H. 2015a. Seasonal variation in contents of sugars in different parts of broccoli. Korean Journal of Horticultural Science and Technology 33(2):276-282. doi:10.7235/hort.2015.14158.

Bhandari, S.R., and Kwak, J.H. 2015b. Chemical composition and antioxidant activity in different tissues of Brassica vegetables. Molecules 20:1228-1243. doi:10.3390/molecules20011228.

Bhandari, S.R., Rhee, J., Choi, C.S., Jo, J.S., Shin, Y.K., and Lee, J.G. 2020. Profiling of individual desulfo-glucosinolate content in cabbage head (Brassica oleracea var. capitata) germplasm. Molecules 25:1860. doi:10.3390/molecules25081860.

Cartea, M.E., Velasco, P., Obregon, S., Padilla, G., and de Haro, A. 2008. Seasonal variation in glucosinolate content in Brassica oleracea crops in northwestern Spain. Phytochemistry 69:403-410. doi:10.1016/j.phytochem.2007.08.014.

Cervenski, J., Gvozdanovic-Varga, J., Vasic, M., and Glogovac, S. 2010. Multivariate analysis for head weight and yield performance of experimental cabbage hybrids (Brassica oleracea var. capitata L.) Genetica 42(2):259-266. doi:10.2298/GENSR1002259C.

Choi, S.-H., Park, S., Lim, Y.P., Kim, S.-J., Park, J.-T., and An, G. 2014. Metabolite profiles of glucosinolates in cabbage varieties (Brassica oleracea var. capitata) by season, color, and tissue position. Horticulture, Environment and Biotechnology 55(3):237-247. doi:10.1007/s13580-014-0009-6.

Ciereszko, I. 2018. Regulatory roles of sugars in plant growth and development. Acta Societatis Botanicorum Poloniae 87(2):3583. doi:10.5586/asbp.3583.

Ciska, E., Drabinska, N., Narwojsz, A., and Honke, J. 2016. Stability of glucosinolates and glucosinolate degradation products during storage of boiled white cabbage. Food Chemistry 203:340-347. doi:10.1016/j.foodchem.2016.02.079. 
De Mortel, P.V. 2018. Genetic analysis of leaf and head morphology traits in heading cabbage (B. oleracea). 61 p. Plant Breeding MSc thesis. Plant Breeding Department, Wageningen University, Wageningen, The Netherlands.

El-Esawi, M., Bourke, P., Germaine, K., and Malone, R. 2012. Assessment of morphological variation in Irish Brassica oleracea species. Journal of Agricultural Science 4(10):20-34. doi:10.5539/jas.v4n10p20.

Eveland, A.L., and Jackson, D.P. 2012. Sugars, signaling, and plant development. Journal of Experimental Botany 63(9):33673377. doi:10.1093/jxb/err379.

Garcia-Diaz, Y.D., Aquino-Bolanos, E.N., Chavez-Servia, J.L., Vera-Guzman, A.M., and Carrillo-Rodriguez, J.C. 2018. Bioactive compounds and antioxidant activity in the common bean are influenced by cropping season and genotype. Chilean Journal of Agricultural Research 78:255-265. doi:10.4067/S0718-58392018000200255.

Joesten, M., Castellion, M.E., and Hogg, J.L. 2007. The world of chemistry: Essentials. $4^{\text {th }}$ ed. Thomson Brooks/Cole, Belmont, California, USA.

Keunen, E., Peshev, D., Vangronsveld, J., Ende, W.V.D., and Cuypers, A. 2013. Plant sugars are crucial players in the oxidative challenge during abiotic stress: extending the traditional concept. Plant, Cell and Environment 36:1242-1256. doi:10.1111/pce.12061.

Kibar, B., Karaagac, O., and Kar, H. 2016. Determination of morphological variability among cabbage (Brassica oleracea var. capitata L.) hybrids and their parents. Igdir University Journal of the Institute of Science and Technology 6(1):31-44. doi:10.21597/jist.2016119273.

Korean Statistical Information Service. 2018. Agriculture, forestry and fishery survey. Daejeon, Republic of Korea. Available at http://kosis.kr/ (accessed 1 June 2020).

Koss-Mikolajczyk, I., Kusznierewicz, B., Wiczkowski, W., Platosz, N., and Bartoszek, A. 2019. Phytochemical composition and biological activities of differently pigmented cabbage (Brassica oleracea var. capitata) and cauliflower (Brassica oleracea var. botrytis) varieties. Journal of the Science of Food and Agriculture 99:5499-5507. doi:10.1002/jsfa.9811.

Magwaza, L.S., and Opara, U.L. 2015. Analytical methods for determination of sugars and sweetness of horticultural crops- A review. Scientia Horticulturae 184:179-192. doi:10.1016/j.scienta.2015.01.001.

Nilsen, E.T., and Orcutt, D.M. 1996. Physiology of plants under stress: abiotic stress. John Wiley and Sons, New York, USA.

Park, S.Y., Arasu, M.V., Lee, M.-K., Chun, J.-H., Seo, J.M., Lee, S.-W., et al. 2014. Quantification of glucosinolates, anthocyanins, free amino acids, and vitamin C in inbred lines of cabbage (Brassica oleracea L.) Food Chemistry 145:7785. doi:10.1016/j.foodchem.2013.08.010.

Pessoa, M.F., Scotti-Campos, P., Pais, I., Feteiro, A., Canuto, D., Simoes, M., et al. 2016. Nutritional profile of the Portuguese cabbage (Brassica oleracea L. var. costata) and its relationship with the elemental soil analysis. Emirates Journal of Food and Agriculture 28(6):381-388. doi:10.9755/ejfa.2016-04-338.

Ribeiro, T., Rovaris, S.R.S., Esteves, J.A.F., Carbonell, S.A.M., and Chiorato, A.F. 2019. Selection of common bean lines obtained by the genealogical and bulk methods for disease resistance and agronomic traits. Chilean Journal of Agricultural Research 79:456-463. doi:10.4067/S0718-58392019000300456.

Rosa, E., David, M., and Gomes, M.H. 2001. Glucose, fructose and sucrose content in broccoli, white cabbage and Portuguese cabbage grown in early and late seasons. Journal of the Science of Food and Agriculture 81:1145-1149. doi:10.1002/jsfa.919.

Samec, D., Pavlovic, I., and Salopek-Sondi, B. 2017. White cabbage (Brassica oleracea var. capitata f. alba): botanical, phytochemical and pharmacological overview. Phytochemistry Reviews 16:117-135. doi:10.1007/s11101-016-9454-4.

Schonhof, I., Krumbein, A., and Bruckner, B. 2004. Genotypic effects on glucosinolates and sensory properties of broccoli and cauliflower. Nahrung-Food 48(1):25-33. doi:10.1002/food.200300329.

Serraj, R., and Sinclair, T.R. 2002. Osmolyte accumulation: can it really help increase crop yield under drought conditions? Plant Cell and Environment 25:333-341. doi:10.1046/j.1365-3040.2002.00754.x.

Singh, B.K., Sharma, S.R., Kalia, P., and Singh, B. 2010. Character association and path analysis of morphological and economic traits in cabbage (Brassica oleracea var. capitata). Indian Journal of Agricultural Science 80(2):116-118.

Sung, S.S., Sheih, W.J., Geiger, D.R., and Black, C.C. 1994. Growth, sucrose synthase, and invertase activities of developing Phaseolus vulgaris L. fruits. Plant, Cell and Environment 17(4):419-426. doi:10.1111/j.1365-3040.1994.tb00310.x.

Terry, P., Wolk, A., Persson, I., and Magnusson, C. 2001. Brassica vegetables and breast cancer risk. Journal of the American Medical Association 285:2975-2977. doi:10.1001/jama.285.23.2975.

VandenLangenberg, K.M., Bethke, P.C., and Nienhuis, J. 2012. Patterns of fructose, glucose, and sucrose accumulation in snap and dry bean (Phaseolus vulgaris) pods. HortScience 47(7):874-878.

Weerakoon, S.R., and Somaratne, S. 2011. Seasonal variation of growth and yield performance of mustard (Brassica juncea (L.) Czern \& Coss) genotypes in Sri Lanka. Journal of Agricultural Sciences 6(1):1-15.

Williams, D.J., Edwards, D., Hamernig, I., Jian, L., James, A.P., Johnson, S.K., et al. 2013. Vegetables containing phytochemicals with potential anti-obesity properties: a review. Food Research International 52:323-333. doi:10.1016/j.foodres.2013.03.015.

Wu, Q.J., Yang, Y., Vogtmann, E., Wang, J., Han, L.H., Li, H.L., et al. 2013. Cruciferous vegetables intake and the risk of colorectal cancer: a meta-analysis of observational studies. Annals of Oncology 24:1079-1087. doi:10.1093/annonc/mds601.

Zhao, Y., Yue, Z., Zhong, X., Lei, J., Tao, P., and Li, B. 2020. Distribution of primary and secondary metabolites among the leaf layers of headed cabbage (Brassica oleracea var. capitata). Food Chemistry 312:126028. doi:10.1016/j.foodchem.2019.126028. 